\title{
The control system for special preparedness of cyclists
}

\author{
Kolumbet A.N. ${ }^{1}$, Dudorova L.Y. ${ }^{1}$, Babina N.A. ${ }^{1}$, Bazulyuk T.A. ${ }^{1}$, Maximovich N.Y. ${ }^{2}$ \\ ${ }^{1}$ Kyiv National University of Technologies and Design, Ukraine \\ ${ }^{2}$ Kiev Institute of Intellectual Property and Law of the National University «Odessa Law Academy», Ukraine
}

\begin{abstract}
Purpose:

to develop a system for monitoring the level of special preparedness of cyclists (specialized in individual race for $4 \mathrm{~km}$ ) on the basis of the indicators of the cardiorespiratory system.

Material: $\quad$ The study involved bicyclists ( $n=14$, age 18-22 years).

Results: $\quad$ The step-increasing load to the full allows to determine the maximum functional opportunities of the body of cyclists. The coefficient of efficiency of the functioning of the cardiovascular system is equal to the ratio of the average distance value of the pulse to the maximum value of the pulse. Using the linear regression equation, it is possible to predict the magnitude of the pulse at a given speed of movement.

Conclusions: It is possible to find out the individual characteristics of athletes with the help of an indicator of the effectiveness of the functioning of the cardiovascular system. One can compare the activity of the cardiovascular system of athletes of different qualifications, different age groups, gender, level of preparedness. The degree of realization of the functionality of cyclists is calculated by a special formula and serves to monitor the training and competitive process. The results of the studies make it possible to predict the result by evaluating the level of special physical preparation.

Keywords: cycling, pulse, control system, prognosis, success.
\end{abstract}

\section{Introduction}

The problem of testing athletes is one of the most urgent in modern sports and should be solved on the basis of achievements in physiology, biochemistry, biomechanics, pedagogy and other sciences [2, 3, 38, 39]. It is impossible to control the process of training athletes without objective criteria for assessing the level of special preparedness $[8,17,25,40]$. The authors note the need to take into account the functional capabilities of the cardiovascular and respiratory systems of the body.

One of the most informative indicators of the functional state of the body of athletes (specializing in sports for endurance) is the level of maximum oxygen consumption $[16,36]$. In studies of foreign authors found that the most informative indicators in assessing the functional readiness of athletes of high qualification is: the magnitude of the oxygen cost of one meter of the path at a standard speed [11, 37]; oxygen consumption level $\left(\mathrm{Vo}_{2}\right)$ at speed of movement $85-90 \%$ from the competitive; speed of movement along the threshold level of anaerobic exchange.

Hydren J.R. and Cohen B.S. showed the possibility of achieving maximum effectiveness in endurance exercises in highly qualified athletes [19]. Mueller S.M. et al. found that aerobic intensive interval training improves cardiovascular ability, but it can reduce the endurance of cycling [26]. Nakahara H. et al. examined the effects of intensive interval training at a frequency of once a week on cardio-respiratory function at rest and during exercise [27]. The authors found that intensive interval training markedly improves cardiorespiratory function and causes morphological adaptations of the heart.

In cycling the methods of modeling are used in various studies. Caddy $O$. et al. used computerized planimetry and compiled a reverse integration model to (c) Kolumbet A.N., Dudorova L.Y., Babina N.A., Bazulyuk T.A., Maximovich N.Y, 2017

doi:10.15561/18189172.2017.0602 simulate a 4-kilometer distance [12]. The authors showed the possibility of a small and significant increase in productivity at a distance of $4 \mathrm{~km}$. Childers W.L. et al. compiled a race model for $4 \mathrm{~km}$ using the Monte Carlo method [13]. The authors established a relationship between power losses and aerodynamic coefficients. Luth M.T. et al. used modeling techniques to study the relationship between passion, normative orientation and the satisfaction of qualified cyclists [24]. These data show that not all forms of passion are useful for classes. Data helps explain the relationship between passion and satisfaction.

Improving the performance of athletes requires: individual approaches to training [15], proper pedagogical control [14], selection of adequate tests [29], optimization of physical activities [28, 32], observance of rest and training regimes [31], accounting of the body's functional reserves [33], predicting the success of athletes [20, 30], the use of rehabilitation means and readaptation to work $[34,35]$.

Some researchers $[22,36]$ notice that during examining a homogeneous group of athletes using standard tests, the maximum oxygen consumption value has a low correlation with the athletic result. In their opinion, testing should be carried out in conditions that are as close as possible to those that are competitive in terms of the structure of the movement and the duration of the task. Under such conditions the factors that limit the availability of work will manifest.

The purpose of the study is to develop a system for monitoring the level of special preparedness of cyclists (specializing in individual race for $4 \mathrm{~km}$ ) on the basis of indicators of the cardiorespiratory system.

\section{Materials and methods}

Participants. The study involved bicyclists $(n=14$, age 18-22 years). Athletes had sports qualification as 
a candidate for master of sports and master of sports. Athletes specialize in individual race at $4 \mathrm{~km}$.

Organization of the study.

To determine the maximum functional opportunities of the cardiorespiratory system of the body of cyclists was used step-increasing load to the full. The cyclists performed work with a pedaling frequency of 90 revolutions per minute using the veloergometer "Monark". The load increased by $2,70 \mathrm{kGm} / \mathrm{min}$. every 2 minutes [21-23]. At the same time an analysis of exhaled air was carried out on the automatic gas analyzer of the company "Beckman". The pulse rate was determined by the electrocardiographic method (electrocardiograph "Salut"). Prior to work and on the 3rd minute of recovery, was dipped blood sampling to determine the acid-base balance $(\mathrm{pH})$.

To determine the level of cardiovascular system functioning, bicyclists participated in competition, where the pulse was recorded throughout the race using the Puls6 radiotelemetric system.

To determine the dependence of the pedaling speed from the intensity of the functioning of the cardiovascular system, cyclists performed a special test program on the track in 5 pulse regimes $(130,150,160,170,180 \mathrm{bpm}$, $4 \mathrm{~km}$ distance). The work with the constant value of the functioning of the cardiovascular system was simulated. The time of passage of each half of the circle $(166,7$ $m)$ and the average speed over the entire distance were measured.

To maintain a certain heart rate in studies was used autocarillary ACL-75, which provided standard testing conditions for all athletes.

Statistical analysis. Average values of indicators and their errors $(\mathrm{X} \pm \mathrm{m})$, degree of difference of means and reliability of differences ( $t, p)$ were determined. The amount of dispersion was set $-\mathrm{a}$ variant around the mean $(\sigma, \mathrm{CV})$. The degree of interrelation between the studied indicators (r) was determined.

In carrying out complex pedagogical, biomechanical and biological surveys with the participation of athletes adhered to the legislation of Ukraine on health protection, the Helsinki Declaration of 2000, directive No. 86/609 of the European Society on the participation of people in biomedical researches.

\section{Results}

At the carrying out step-increasing load to full, a bicycle ergometer obtained the data (Table 1). The data allow to judge individual characteristics of the activity of the cardiorespiratory system of the cyclists' body.

The values of the obtained indices testify to the maximum stress of the functioning of the examined systems of athletes' organism. The correlation relationship of studied parameters with the results in the individual race at $4 \mathrm{~km}$ is unreliable (with the exception of the pulse rate). Therefore, it is impossible to use these data to predict the sports result (Table 2).

Step-increasing load to full allows to determine the maximum functionality of the cyclists' body. The maximum value of the pulse in the test has a negative value of the correlation coefficient and the sports result $\left(r_{t k}=-0,578, \mathrm{p}<0.1\right)$. This indicates an inverse relationship between the studied indicators. Excessive increase in the pulse when performing work on a veloergometer indicates an ineffective activity of the cardiovascular system. To determine the level of functioning of the cardiovascular

Table 1. The indices of the maximum functional capabilities of the cardiorespiratory system of the organism of cyclists in step-increasing load to full

\begin{tabular}{|c|c|c|c|c|c|c|}
\hline & $\begin{array}{l}\text { Indices } \\
\text { physiological }\end{array}$ & & & & biochemical & \\
\hline Parameters & $\begin{array}{l}\text { MMV } \\
\text { (I) }\end{array}$ & $\begin{array}{l}\mathrm{Vo}_{2} \text { max } \\
\text { (I) }\end{array}$ & $\begin{array}{l}\mathrm{Vo}_{2} \\
(\mathrm{ml} / \mathrm{kg})\end{array}$ & $\begin{array}{l}f_{h} \\
\text { (bpm) }\end{array}$ & $\begin{array}{l}\mathrm{pH} \\
\text { before the } \\
\text { load }\end{array}$ & $\begin{array}{l}\mathrm{pH} \\
\text { after the } \\
\text { load }\end{array}$ \\
\hline$x$ & 151,811 & 4,441 & 63,112 & 198,611 & 7,381 & 7,216 \\
\hline$\sigma$ & 31,242 & 0,539 & 6,941 & 2,760 & 0,012 & 0,076 \\
\hline$m$ & 11,811 & 0,204 & 2,620 & 1,040 & 0,005 & 0,029 \\
\hline
\end{tabular}

Notes: MMV - maximum pulmonary ventilation (I); Vo2 max - maximum consumption of oxygen (I); Vo2 - oxygen consumption $(\mathrm{ml} / \mathrm{kg})$; fh - pulse (bpm)

Table 2. Coefficients of correlation between the investigated parameters of the cardiorespiratory system of the body of athletes and the result in the race for $4 \mathrm{~km}$

\begin{tabular}{lllll}
\hline $\begin{array}{l}\text { Investigated } \\
\text { parameters }\end{array}$ & $\begin{array}{l}\mathrm{Vo}_{2} \max \\
(\mathbf{l} / \mathbf{m i n})\end{array}$ & $\begin{array}{l}\mathrm{Vo}_{2} \\
(\mathbf{m l} / \mathbf{k g} / \mathbf{m i n})\end{array}$ & $\begin{array}{l}\mathbf{f}_{\mathbf{h}^{\prime}} \\
(\mathbf{b p m})\end{array}$ & $\mathbf{p H}$ \\
\hline Speed in race, $(\mathrm{m} / \mathrm{s})$ & 0,320 & 0,390 & $-0,578$ & 0,442 \\
& unreliable & unreliable & $\mathrm{p}<0,1$ & unreliable \\
\hline
\end{tabular}

Notes: Vo2 max - maximum oxygen consumption (l/ $\mathrm{min}$ ); Vo2 - oxygen consumption ( $\mathrm{ml} / \mathrm{kg} / \mathrm{min}$ ); fh - pulse (bpm); $p$ - level of significance of the correlation coefficient 
system of cyclists in conditions of competitive activity, the pulse rate was used during the individual pursuit race at $4 \mathrm{~km}$ (Table 3).

Three indicators are calculated that characterize the intensity of the functioning of the cardiovascular system.

1. The average distance of the pulse is 184,9 beats per minute: characterizes the level of functioning of the cardiovascular system of cyclists in the race for $4 \mathrm{~km}$. This value has a negative relationship with the result in the race. The correlation coefficient is equal to $r_{t k}=-0,440$.

2. The value of the pulse at the 1st minute of the work reflects the speed of the cardiovascular system and the entire organism as a whole. It is to the $40-60^{\text {th }}$ second of the work that anaerobic and aerobic energy supply mechanisms are fully activated. In our study, the pulse at the $1^{\text {st }}$ minute of work was $172.1 \pm 8.7 \mathrm{bpm}$.

3. The maximum pulse value reflects the maximum level of functioning of the cardiovascular system. The maximum pulse value is $192 \pm 5.29 \mathrm{bpm}$ : correlates $\left(r_{t k}\right.$ $=0.78, \mathrm{p}<0.1)$ with the maximum pulse value that was obtained in the bicycle ergometer test in the laboratory. The maximum pulse value has a negative correlation coefficient with the result in the race $\left(r_{t k}=-0,515 ; \mathrm{p}<0.1\right)$.

The coefficient of efficiency of the functioning of the cardiovascular system $\left(C E_{p}\right)$ is equal to the ratio of the average distance value of the pulse $\left(f_{h \Delta}\right)$ to the maximum value of the pulse $\left(f_{h \max }\right)$ :

$$
\begin{gathered}
C E_{p}=\left(f_{h \Delta} / f_{h \max }\right) \times 100 \%, \\
C E_{p}=(184,9 / 192,0) \times 100 \%=96,3 \% .
\end{gathered}
$$

The lower the value of the efficiency factor, the more effectively the cardiovascular system of athletes works. This indicator $\left(C E_{p}\right)$ will be more informative if it is calculated taking into account the average speed. Using the indicator $C E_{p}$, it is possible to compare the activity of the cardiovascular system of athletes of different qualifications, different age groups, gender, and level of preparedness. This allows to find out the individual characteristics of athletes.

The level of functioning of the cardiovascular system of cyclists in the race (according to the pulse rate for the $1^{\text {st }}$ minute and the maximum pulse) is close to the limiting level (as in the laboratory). After the period of operation $(60-90 \mathrm{~s})$, the pulse curve is practically maintained at the same level - 182,34-189,4 bpm. In this case, there is an insignificant increase in the pulse at the finish: $192,0 \pm 5,3 \mathrm{bpm}$. The dynamics of the speed of movement is more variable. After the initial acceleration on the $30^{\text {th }}$ $\mathrm{s}$ the speed reaches $13,47 \mathrm{~m} / \mathrm{s}$. Then the speed gradually decreases to $12 \mathrm{~m} / \mathrm{s}$ and again increases at the end of the $5^{\text {th }}$ minute $(11,95 \mathrm{~m} / \mathrm{s})$.

The high informativeness and reliability of the pulse rate in the race was used as a basis for the methodology for assessing the level of special functional readiness of cyclists. The obtained data (Table 4) made it possible to determine the dependence of the speed of movement on the intensity of the cardiovascular system during the passage of a distance of $4 \mathrm{~km}$.

The curved line of change in the speed of movement of cyclists, depending on the level of the pulse, can be described by the equation of linear regression of the type $y=a+b X$. For our study, the equation looks like this:

$$
V=0,0536 X+2,354
$$

where $\mathrm{V}$ - the speed of movement $(\mathrm{m} / \mathrm{s})$

$\mathrm{X}$ - the value of the programmable pulse in bpm.

The coefficients $\boldsymbol{a}$ and $\mathbf{b}$ in the equation are 2,.354 and 0,0536

Equation (I) allows analytically determine the speed of movement, depending on the selected heart rate. The linear regression equation looks like this:

$$
f_{h}=17,883 X-35,480 \text {, }
$$

Table 3. Change in the value of the pulse (fh) of cyclists during an individual pursuit race at $4 \mathrm{~km}$

\begin{tabular}{lllllllll}
\hline Parameters & \multicolumn{2}{l}{ Time of race, $\mathbf{( s )}$} & & & & & \\
& $\mathbf{1 5}$ & $\mathbf{3 0}$ & $\mathbf{6 0}$ & $\mathbf{9 0}$ & $\mathbf{1 2 0}$ & $\mathbf{1 8 0}$ & $\mathbf{2 4 0}$ & $\mathbf{3 0 0}$ \\
\hline$X$ & 134,5 & 159,2 & 172,1 & 182,3 & 184,0 & 187,1 & 189,4 & 192,0 \\
$\sigma$ & 12,7 & 9,8 & 8,8 & 7,4 & 6,8 & 6,2 & 5,5 & 5,3 \\
$m$ & 4,9 & 3,7 & 3,3 & 2,8 & 2,6 & 2,3 & 2,1 & 2,0 \\
\hline
\end{tabular}

Table 4. Change in the speed of the distance $4 \mathrm{~km}$, depending on the pulse

\begin{tabular}{lllllll}
\hline \multirow{2}{*}{ Indices } & \multirow{2}{*}{ Parameters } & \multicolumn{2}{l}{ Pulse regimes of work (bpm) } & & & \\
& & $\mathbf{1 3 0}$ & $\mathbf{1 5 0}$ & $\mathbf{1 6 0}$ & $\mathbf{1 7 0}$ & $\mathbf{1 8 0}$ \\
\hline An average & $X$ & 9,136 & 10,497 & 11,177 & 11,550 & 11,733 \\
speed in the & $\sigma$ & 0,281 & 0,162 & 0,163 & 0,096 & 0,104 \\
test, $(\mathrm{m} / \mathrm{s})$ & $m$ & 0,106 & 0,061 & 0,062 & 0,036 & 0,039 \\
PS, (bpm) & - & 0,237 & 0,238 & 0,239 & 0,245 & 0,253 \\
\hline
\end{tabular}

Note: $f_{h}$ - pulse (bpm) 
where $\mathrm{X}$ - the specified speed of movement $(\mathrm{m} / \mathrm{s})$.

The coefficients $\boldsymbol{a}$ and $\boldsymbol{b}$ in the equation are 35,480 and 17,883 .

Using the linear regression equation, it is possible to predict the magnitude of the pulse at a given speed of movement. The disadvantage of this method is to maintain one of the selected parameters (pulse or speed) at a constant level.

In this study, we determined the relationship between the speed of movement at different heart rates (tests $V_{130}$, $V_{150}, V_{160}, V_{170}$ и $V_{180}$ ) and the results that were shown by cyclists in the individual pursuit race at $4 \mathrm{~km}$. In the tests modes of load on the pulse were in the range of various power supply mechanisms.

The speed of cycling in the tests $V_{130}, V_{150}$ and $V_{160}$ is not reliably linked to the results that were shown in the pursuit race at $4 \mathrm{~km}$ (Table 5). In these tests, the body of athletes operates in a moderate and high-power zone (approaching the threshold of anaerobic exchange). The result in the race depends not only on aerobic performance. The result in the race is determined by anaerobic performance. This is taken into account by the work itself in the tests $V_{170}$ and $V_{180^{*}}$ Tests have a high reliable relationship $\left(r_{t k}=0,670\right.$; $p<0,1$ and $\left.r_{t k}=747 ; p<0,1\right)$. This allows them to be used in assessing the level of special preparedness of cyclists.

The obtained data (the correlation between the speed in the race and the speed in the tests $V_{170}$ and $V_{180}$ ) can be described by the linear regression equation:

$$
\begin{aligned}
& V_{170}=766 X+3,616, \\
& V_{180}=1,471 X-4,796,
\end{aligned}
$$

where $\mathrm{V}$ - the predicted speed in the race $(\mathrm{m} / \mathrm{s})$,

A - the speed of movement in the tests $V_{170}$ and $V_{180}(\mathrm{~m} / \mathrm{s})$.

The coefficients $\boldsymbol{a}$ and $\boldsymbol{b}$ in the equation are as follow 4,796 and 1,471.

Equations III and IV allow to predict the result in the race and perform an analysis of the degree of realization of the functional capabilities of the organism, depending on the shown result. The degree of implementation of the functionality is understood as the ratio of the displayed speed in the race $\left(V_{t}\right)$ to the predicted speed for the selected test $V_{170}$ and $V_{180^{\circ}}$.

Lets consider this on the following example: rider $A$ (P-us) in the test $V_{180}$ developed a speed of $11,645 \mathrm{~m} / \mathrm{s}$. On the basis of equation III, the speed in the race must be
$12,33 \mathrm{~m} / \mathrm{s}\left(V_{d}=1,471 \times 11,645-4,796\right)$. In reality, athlete $A$ showed in the race speed of $12,49 \mathrm{~m} / \mathrm{s}$. Hence the degree of implementation of the functionality is:

$$
S R=\left(V_{t} / V_{d}\right) \times 100 \%,
$$

where $V_{t}$ - the real speed in the race $(\mathrm{m} / \mathrm{s})$,

$V_{d}$ - predicted speed in the race $(\mathrm{m} / \mathrm{s})$.

For the rider A (P-us), the degree of realization of the functional capabilities $(S R=12,49: 12,33) \times 100 \%=101,3$. This figure is higher than the average for the group. For the rider $B$ (Sh-ko): in the test $V_{180}$, the speed of movement is $11,634 \mathrm{~m} / \mathrm{s}$; the speed in the race according to equation IV must be $12,32 \mathrm{~m} / \mathrm{s}$. Really, the athlete showed $12,16 \mathrm{~m} / \mathrm{s}$. Consequently, the degree of realization of its functional capabilities $(S R=12,16: 12,32) \times 100 \%$ is $98,7 \%$. Athlete B (Sh-ko) has not realized its potential functionality.

\section{Discussion}

The data obtained by us coordinate with the results of studies of the cardiorespiratory system of cyclists by other investigators [4, 25,37]. In the experiments [11, 17], the obtained data indicated a low efficiency of the cardiovascular system. This is due to the increase in the pulse when doing work on a veloergometer. It is known that the magnitude of the pulse reflects not only the adaptation of the human body to the load $[6,7]$. Pulse is an important indicator of the cardiovascular system. The pulse affects the amount of minute blood volume. According to the data of [7], the magnitude of the minute volume of blood is mainly increased due to the increase in the pulse rate.

Beattie K. et. al. investigated the effect of a 20week maximum and explosion-force training effect on explosive force, VO (2) max, body composition of cyclists [9]. The study demonstrates that 20 weeks of such training can significantly improve the maximum strength, the specific explosive force of a bicycle and the maximum oxygen consumption of cyclists. Borges N.R. et. al. studied autonomic cardiovascular modulation in welltrained masters and young cyclists after a high-intensity interval training [10]. The authors found that the physical training of qualified athletes has a significant effect on the autonomous function. These data are confirmed by our research.

The data obtained by us are confirmed in the works of other researchers, who also simulated various versions

\begin{tabular}{|c|c|c|c|c|c|}
\hline \multirow{2}{*}{ Indices } & \multicolumn{5}{|c|}{ The speed of movement in the test $(\mathrm{m} / \mathrm{s})$} \\
\hline & 130 & 150 & 160 & 170 & 180 \\
\hline $\begin{array}{l}\text { The size of } \\
\text { correlation } \\
\text { coefficient } \\
(r)\end{array}$ & $\begin{array}{l}0,390 \\
\text { unreliable }\end{array}$ & $\begin{array}{l}0,420 \\
\text { unreliable }\end{array}$ & $\begin{array}{l}0,510 \\
\text { unreliable }\end{array}$ & $\begin{array}{l}0,670 \\
p<0,1\end{array}$ & $\begin{array}{l}0,747 \\
p<0,1\end{array}$ \\
\hline
\end{tabular}
of the distribution of the athletes' efforts in an individual

Table 5. Correlation of the speed of movement of cyclists in the tests and results in the individual pursuit race at $4 \mathrm{~km}$

Note: $p$ - level of significance 
pursuit race at $4 \mathrm{~km}$ [1]. A similar character of the dynamics of the pulse and the power of pedaling was obtained earlier [2]. The authors modeled the speed for individual pursuit at $4 \mathrm{~km}$ on a bicycle ergometer for cyclists of different age groups. Hittinger E.A. et. al. determined the effect of the MOC (maximum oxygen consumption) on peak loads, submaximal and peak cardiovascular hemodynamics, and the saturation of peripheral capillary oxygen under simulated conditions in experienced cyclists [18]. The authors found that ischemic pre-conditioning can improve blood flow and oxygen delivery to tissues (including skeletal muscles) and has the potential to improve intense aerobic exercise.

However, the predicted result in the race according to equation (IV) based on the test $V_{180}$ reflects only the contribution of the functional readiness of cyclists. This result does not take into account the influence:
- moral-strong-willed qualities and mental properties of personality [5];

- the level of tactical preparedness [2].

\section{Conclusions}

1. Using the indicator $C E_{p}$, it is possible to compare the activity of the cardiovascular system of athletes of different qualifications, different age groups, gender, and level of preparedness. This allows to find out the individual characteristics of athletes.

2. The degree of realization of the functionality of cyclists is calculated by a special formula. The formula serves to control the training and competitive process.

3 . The results of the research allow to predict the result by evaluating the level of special physical training.

\section{Conflict of interest}

The authors state that there is no conflict of interest.

\section{References}

1. Andriunin MA, Golovachev AI, Krylatykh IuG, Utkin VL. The efficiency of the cyclist's work in modeling an individual pursuit race at $4 \mathrm{~km}$ with different force distribution options. Velosipednyj sport, 1981:44-46.

2. Golovachev AI, Krylatykh IuG. Control over the tactical preparedness of young cyclists in individual pursuit. Velosipednyj sport, 1982:42-46. (in Russian)

3. Krasnikov AA, Krylatykh IuG. Methods of research in cycling. Velosipednyj sport, 1972:108-116. (in Russian)

4. Krylatykh IuG. Determination of starting acceleration, optimal distance and pace of pedaling in individual pursuit at $4 \mathrm{~km}$. Velosipednyj sport, 1980:18-21. (in Russian)

5. Puni AC. Essays on the psychology of sports, 1959. (in Russian)

6. Rozenblat VV. The problem of fatigue in sports, 1961. (in Russian)

7. Farfel' VS. Endurance and sports fatigue at a distance. Teoriia i praktika fizicheskoj kul 'tury, 1969;1:43. (in Russian)

8. Banister EW, Jackson RC (1967). The effect of speed and load changes on oxygen intake for equivalent power outputs during bicycle ergometry. European Journal of Applied Physiology, 1967;24:284-90.

9. Beattie K, Carson BP, Lyons M, Kenny IC. The Effect of Maximal- and Explosive-Strength Training on Performance Indicators in Cyclists. International Journal of Sports Physiology and Performance. 2017;12(4):470-80.

10.Borges NR, Reaburn PR, Doering TM, Argus CK, Driller MW. Autonomic cardiovascular modulation in masters and young cyclists following high-intensity interval training. Clinical Autonomic Research. 2017;27(2):83-90.

11.Buning D, Gunen Y, Maassen N (1984). Relationship between work load, pedal frequency, and physical fitness. International Journal of Sports Medicine, 1984;5:92-97.

12.Caddy O, Fitton W, Symons D, Purnell A, Gordon D. The effects of forward rotation of posture on computersimulated 4-km track cycling: Implications of Union Cycliste Internationale rule 1.3.013. Proceedings of the Institution of Mechanical Engineers Part P-Journal of Sports Engineering and Technology. 2017;231(1):3-13.

13.Childers WL, Gallagher TP, Duncan JC, Taylor DK. Modeling the Effect of a Prosthetic Limb on 4-km Pursuit Performance. International Journal of Sports Physiology and
Performance. 2015;10(1):3-10.

14.Drogomeretsky VV, Kopeikina EN, Kondakov VL, Iermakov SS. Adaptation of Ruffier's test for assessment of heart workability of students with health problems. Pedagogics, psychology, medical-biological problems of physical training and sports, 2017; 21(1): 4-10. doi:10.15561/18189172.2017.0101

15.Druz VA, Iermakov SS, Artemyeva GP, Puhach YI, Muszkieta R. Individualization factors of students' physical education at modern stage of its realization. Physical education of students, 2017; 21(1): 10-16. doi:10.15561/20755279.2017.0102

16.Dua JS, Cooper AR, Fox KR, Graham Stuart A. Physical activity levels in adults with congenital heart disease. European Journal of Cardiovascular Prevention \& Rehabilitation 2007;14:287-293.

17.Francis KT, McClatchey PR, Sumsion JR, Hansen DE. The relationship between anaerobic threshold and heart rate linearity during cycle ergometry. European Journal of Applied Physiology, 1989;59:273-277.

18.Hittinger EA, Maher JL, Nash MS, Perry AC, Signorile JF, Kressler J, et al. Ischemic preconditioning does not improve peak exercise capacity at sea level or simulated high altitude in trained male cyclists. Applied Physiology Nutrition and Metabolism. 2015;40(1):65-71.

19.Hydren JR, Cohen BS. Current scientific evidence for a polarized cardiovascular endurance training model. Journal of Strength and Conditioning Research. 2015;29(12):352330.

20.Iermakov SS, Podrigalo LV, Jagiello W. Hand-grip strength as an indicator for predicting the success in martial arts athletes. Archives of Budo. 2016;12:179-86.

21.Kolumbet AN, Natroshvili SG, Babyna TG. The biomechanics aspects of adaptation the system of motions of highly skilled bicyclists in the process of contention activity. Physical Education of Students, 2017;5:272-277.

22.Kolumbet AN. Dynamic of kayak rowing technique in the process of competition activity. Pedagogics, psychology, medical-biological problems of physical training and sports, 2017; 21(4): 175-179. doi:10.15561/18189172.2017.0405

23.Kolumbet AN. Study of qualified cyclists movements' coordination structure in period of overcoming fatigue during differently oriented trainings. Physical education of students, 2017; 21(2): 72-77. doi:10.15561/20755279.2017.0204 
24.Luth MT, Flinchbaugh CL, Ross J. On the bike and in the cubicle: The role of passion and regulatory focus in cycling and work satisfaction. Psychology of Sport and Exercise. 2017;28:37-45.

25.Mozaffarian D, Furberg CD, Psaty BM, Siscovick D. Physical activity and incidence of atrial fibrillation in older adults: the Cardiovascular Health Study. Circulation, 2008;118:800-807.

26. Mueller SM, Aguayo D, Zuercher M, Fleischmann O, Boutellier U, Auer M, et al. High-Intensity Interval Training with Vibration as Rest Intervals Attenuates Fiber Atrophy and Prevents Decreases in Anaerobic Performance. Plos One. 2015;10(2).

27.Nakahara H, Ueda SY, Miyamoto T. Low-Frequency SevereIntensity Interval Training Improves Cardiorespiratory Functions. Medicine and Science in Sports and Exercise. 2015;47(4):789-98.

28.Osipov AY, Kudryavtsev MD, Iermakov SS, Jagiello W. Topics of doctoral and postdoctoral dissertations devoted to judo in period 2000-2016 - the overall analysis of works of Russian experts. Arch Budo, 2017; 13: 1-10

29. Osipov AYu, Kudryavtsev MD, Iermakov SS, Yanova MG, Lepilina TV, Plotnikova II, Dorzhieva OS. Comparative analysis of effectiveness of some students' physical culture training methodic. Physical education of students, 2017; 21(4): 176-181. doi:10.15561/20755279.2017.0405

30.Podrigalo LV, Galashko M N, Iermakov SS, Rovnaya OA, Bulashev AY. Prognostication of successfulness in armwrestling on the base of morphological functional indicators' analysis. Physical education of students, 2017; 21(1): 46-51. doi:10.15561/20755279.2017.0108

31.Podrigalo LV, Iermakov SS, Avdiievska OG, Rovnaya OA, Demochko HL. Special aspects of Ukrainian schoolchildren's eating behavior. Pedagogics, psychology, medical-biological problems of physical training and sports, 2017; 21(3): 120125. doi:10.15561/18189172.2017.0304

32.Podrigalo LV, Iermakov SS, Jagiełło W. Special indices of body composition as a criterion of somatic development of martial arts practitioners. Arch Budo Sci Martial Art Extreme Sport, 2017; 13: 5-12

33.Pryimakov AA, Eider E, Nosko MO, Iermakov SS. Reliability of functioning and reserves of system, controlling movements with different coordination structure of special health group girl students in physical education process. Physical education of students, 2017; 21(2): 84-89. doi:10.15561/20755279.2017.0206

34.Radziminska A, Weber-Rajek M, Lulinska-Kuklik E, Kazmierczak U, Moska W. Academic youth's health behavior. Physical education of students, 2016; 20(6): 55-62. doi:10.15561/20755279.2016.0607

35.Radzimińska A, Weber-Rajek M, Lulińska-Kuklik E, Piecka P, Moska W. The impact of classical massage on spine mobility. Pedagogics, psychology, medical-biological problems of physical training and sports, 2017; 21(2): 82-86. doi:10.15561/18189172.2017.0206

36.Swift DL, Lavie CJ, Johannsen NM, et al. Physical activity, cardiorespiratory fitness, and exercise training for the in primary and secondary coronary prevention. Circulation, 2013;77:281-92.

37.Thompson PD, Franklin BA, Balady GJ, et al. Exercise and acute cardiovascular events placing the risks into perspective: a scientific statement from the American Heart Association Council on Nutrition, Physical Activity, and Metabolism and the Council on Clinical Cardiology. Circulation, 2007; 115:2358-2368.

38.Jagiello W, Sawczyn S, Jagiello M. The subjective profile of positive health and survival abilities in women differing as to physical activity. Archives of Budo. 2012;8(4):219-24.

39.Sawczyn S, Mishchenko V, Moska W, Sawczyn M, Jagiello M, Kuehne T, et al. Strength and aerobic training in overweight females in Gdansk, Poland. Open Medicine. 2015;10(1):152-62.

40.Wolyniec W, Ratkowski W, Urbanski R, Bartoszewicz M, Wolyniec Z, Siluk D, et al. Urinary kim-1 but not urinary ngal is increased after short maximal exercise. Nephrology Dialysis Transplantation. 2016;31:149-149.

\section{Information about the authors:}

Kolumbet A.N.; http://orcid.org/0000-0001-8775-4232; re_play @3g.ua; Kyiv National University of Technologies and Design; Nemirovich-Danchenko Street, 2, Kyiv 01011, Ukraine.

Dudorova L.Y.; http://orcid.org/0000-0002-6263-4995; vykh46@i.ua; Kyiv National University of Technologies and Design; Nemirovich-Danchenko Street, 2, Kyiv 01011, Ukraine.

Babina N.A.; http://orcid.org/0000-0001-9777-4827; babynatg @3mail.ru;; Kyiv National University of Technologies and Design; Nemirovich-Danchenko Street, 2, Kyiv 01011, Ukraine.

Bazulyuk T.A.; http://orcid.org/0000-0002-6244-6302; baziluk@rambler.ru; Kyiv National University of Technologies and Design; Nemirovich-Danchenko Street, 2, Kyiv 01011, Ukraine.

Maximovich N.Y.; http://orcid.org/0000-0002-7405-9801; natalimaximovich@i.ua; Kiev Institute of Intellectual Property and Law of the National University «Odessa Law Academy»; Kharkov highway, 210, Kiev, 02121, Ukraine.

Cite this article as: Kolumbet AN, Dudorova LY, Babina NA, Bazulyuk TA, Maximovich NY. The control system for special preparedness of cyclists. Pedagogics, psychology, medical-biological problems of physical training and sports, 2017;21(6):266271. doi:10.15561/18189172.2017.0602

The electronic version of this article is the complete one and can be found online at: http://www.sportpedagogy.org.ua/index.php/PPS/issue/archive

This is an Open Access article distributed under the terms of the Creative Commons Attribution License, which permits unrestricted use, distribution, and reproduction in any medium, provided the original work is properly cited (http://creativecommons.org/licenses/by/4.0/deed.en).

Received: 16.07.2017

Accepted: 02.08.2017; Published: 05.11.2017 